\title{
PENINGKATAN KOMPETENSI MANAJERIAL KEPALA MADRASAH DALAM MEMPERSIAPKAN AKREDITASI MELALUI PENDAMPINGAN MODEL "BERKAT EVADIR BISA"
}

\author{
Amin Sarwati \\ Pengawas Sekolah pada Madrasah Aliyah di Kabupaten Sragen \\ aminsarwati@yahoo.com
}

\begin{abstract}
This study aims to improve the managerial competence of the head of madrasah in preparing accreditation through mentoring "BERKAT EVADIR BISA" model which is an acronym of "bedah perangkat, evaluasi diri, bimbingan intensif dan simulasi akreditasi". This research is a school action research with subject of head of madrasah along with teacher and educational staff in three Madrasah Aliyah (MA) assisted that will do re-accreditation in 2017 that is MA Nurul Huda Gondang, MA NU Gondang and MA Al Hikmah Tanon. This study consists of two cycles; each cycle consists of four stages: planning, action, acting, observing, and reflection. The research period was 4 months from February to May 2017. The results showed that with the mentoring of "BERKAT EVADIR BISA" the accreditation preparation value of the three MA increased from the initial condition to cycle I and cycle II. The data of value increase are respectively $M A N U$ Gondang: initial condition 75; cycle I: 86; and cycle II: 94. MA Nurul Huda Gondang initial condition: 77; cycle I: 85; and cycle II: 95. MA Al Hikmah Tanon initial conditions: 79; cycle I: 84; and cycle II: 95. Based on the theoretical study and the results of the action, the conclusion of the research result that mentoring the model "BERKAT EVADIR BISA" can improve the competence of madrasah head in preparing accreditation at MA Nurul Huda Gondang, MA NU Gondang and MA Al Hikmah Tanon Year 2017.
\end{abstract}

Keywords: managerial competence, accreditation.

Abstrak. Penelitian ini bertujuan untuk meningkatkan kompetensi manajerial kepala
madrasah dalam mempersiapkan akreditasi melalui pendampingan model "BERKAT
EVADIR BISA"yang merupakan akronim dari "bedah perangkat akreditasi, evaluasi
diri, bimbingan intensif dan simulasi akreditasi". Penelitian ini merupakan school
action research dengan subyek kepala madrasah beserta guru dan tenaga kependidikan
di tiga Madrasah Aliyah (MA) binaan yang akan melakukan reakreditasi pada tahun
2017 yaitu MA Nurul Huda Gondang, MA NU Gondang dan MA Al Hikmah Tanon.
Penelitian ini terdiri dari dua siklus, setiap siklus terdiri dari empat tahap yaitu
perencanaan (planning), pelaksanaan tindakan (acting), pengamatan (observing), dan
refleksi (reflection). Waktu penelitian selama 4 bulan yaitu Februari sampai dengan
Mei 2017. Hasil penelitian menunjukkan bahwa dengan pendampingan model
"BERKAT EVADIR BISA" nilai persiapan akreditasi ketiga MA tersebut mengalami
peningkatan dari kondisi awal ke siklus I dan siklus II. Data peningkatan nilai
masing-masing adalah MA NU Gondang: kondisi awal 75; siklus I: 86; dan siklus
II: 94. MA Nurul Huda Gondang kondisi awal: 77; siklus I: 85; dan siklus II: 95.
MA Al Hikmah Tanon kondisi awal: 79; siklus I: 84 ; dan siklus II:95. Berdasarkan
kajian teori dan hasil tindakan, simpulan hasil penelitian bahwa pendampingan model
"BERKAT EVADIR BISA"dapat meningkatkan kompetensi kepala madrasah dalam 
mempersiapkan akreditasi pada MA Nurul Huda Gondang, MA NU Gondang dan MA Al Hikmah Tanon Tahun 2017.

Kata kunci: kompetensi manajerial, akreditasi.

\section{Pendahuluan}

\section{A. Latar Belakang Masalah}

Madrasah Aliyah (MA) Nahdatul Ulama Gondang, MA Nurul Huda Gondang dan MA Al Hikmah Tanon adalah tiga madrasah binaan yang oleh BAP S/M Provinsi Jawa Tengah dijadwalkan melaksanakan reakreditasi pada bulan Juni 2017. Selaku pengawas sekolah pembina pada madrasah tersebut sesuai Peraturan Pemerintah Nomor 74 Tahun 2008 tentang Guru, pasal 54 ayat (8) butir d menyatakan bahwa guru yang diangkat dalam jabatan pengawas satuan pendidikan melakukan tugas pembimbingan dan pelatihan profesional guru dan tugas pengawasan. Tugas pengawasan yang dimaksud adalah melaksanakan kegiatan pengawasan akademik dan manajerial. Hal ini seiring dengan Permen PAN dan RB Nomor 14 Tahun 2016 tentang Perubahan atas Permen PAN dan RBNomor 21 Tahun 2010 tentang Jabatan Fungsional Pengawas Sekolah dan Angka Kreditnya Bab II Pasal 5 yang menyatakan bahwa tugas pokok pengawas sekolah adalah melaksanakan tugas pengawasan akademik dan manajerial pada satuan pendidikan.

Dalam melaksanakan tugas pengawasan manajerial tersebut, salah satu tugas pengawas sekolah adalah melaksanakan pembimbingan dan pelatihan profesional kepala madrasahuntuk keterlaksanaan dan pemenuhan delapan Standar Nasional Pendidikan (SNP), termasuk didalamnya adalah akreditasi sekolah.

PeraturanPemerintah Republik Indonesia nomor 13 Tahun 2015 tentang Perubahan Kedua atas Peraturan Pemerintah Nomor 19 Tahun 2005 tentang Standar Nasional Pendidikan, bahwa akreditasi adalah kegiatan penilaian kelayakan program dan/atau satuan pendidikan berdasarkan criteria yang telah ditetapkan.Akreditasi dilaksanakan sebagai bentuk akuntabilitas publik dilakukan secara obyektif, adil,transparan,dankomprehensif dengan menggunakan instrument dan criteria yang mengacu kepada SNP yang mencakup: (1) Standar isi; (2) Standar proses; (3) Standar kompetensi lulusan; (4) Standar pendidikdantenagakependidikan; (5) Standar sarana dan prasarana; (6) Standar pengelolaan; (7) Standar pembiayaan;dan (8) Standar penilaian pendidikan.

Terkait dengan tiga madrasahaliyah (MA) binaan yang akan melaksanakan reakreditasi pada Juni 2017tersebut, ketiga kepala madrasah menghadapi tantangan berat karena harus mampu meningkatkan nilai dan peringkat akreditasi periode sebelumnya, yaitu MA Nahdatul Ulama Gondang: 82 (baik); MA Nurul Huda Gondang: 83 (baik) dan MA Al Hikmah Tanon: 90 (amat baik). Tantangan ini semakin berat karena oleh Badan Akreditasi Nasional (BAN) untuk peringkat akreditasi mulai tahun 2017 kriterianya ditingkatkan menjadi sebagai berikut: A (unggul) jika nila akreditasi 91 s.d. 100); B (baik) jika nilai akreditasi 81 s.d. 90; C (cukup) jika nilai akreditasi 71 s.d. 80 .

Untuk melaksanakan tugas pembimbingan kepada kepala madrasah, pengawas sekolah selaku peneliti dituntut mencari strategi yang efektif dan jitu agar nilai dan peringkat reakreditasi dapat meningkat. Menyelaraskan dengan permasalahan yang ada maka peneliti memilih strategi pendampingan model "BERKAT EVADIR BISA" yang merupakan akronim dari "bedah perangkat akreditasi, evaluasi diri, bimbingan intensif dan simulasi akreditasi”.

Pendampingan model "BERKAT EVADIR BISA" ini maksudnya adalah model pendampingan pengawas sekolah yang meliputi empat tahap kegiatan dalam mempersiapkan akreditasi, meliputi: 1) Bedah perangkat (BERKAT); 2) Evaluasi diri (EVADIR); 3) Bimbingan intensif (BI) dan 4) Simulasi akreditasi (SI). Adapun rincian 
kegiatan masing-masing tahap adalah sebagai berikut.

Tahap BERKAT yaitu akronim dari bedah perangkat. Tahap ini pengawas sekolah mengadakan sosialisasi dengan bentuk kegiatan bedah perangkat akreditasi, yang terdiri dari empat perangkat yaitu: 1) Instrumen akreditasi; 2) Petunjuk teknis pengisian instrument akreditasi; 3) Instrumen pengumpulan data dan informasi pendukung dan 4) Teknik penskoran dan pemeringkatan hasil akreditasi.

Tahap EVADIR yaitu evaluasi diri. Tahap ini pengawas sekolah mendampingi kepala madrasah beserta tim akreditasi yang terdiri dari guru dan tenaga kependidikan melakukan penilaian diri secara obyektif terhadap kesiapan akreditasi. Evaluasi diri ini dilakukan tim akreditasi dengan mengisi instrumen akreditasi dibantu dengan software aplikasi penilaian akreditasi.

Tahap BI yaitu bimbingan intensif. Tahap ini pengawas sekolah memberikan bimbingan secara intensif kepada kepalamadrasah beserta tim akreditasi untuk mencermati instrumen dan menyiapkan data dan informasi pendukung akreditasi. Karena cakupan yang luas, mencakup delapan komponen SNP, maka bimbingan intensif dilaksanakan selama 4 kali pertemuan dalam 2 siklus kegiatan.

Tahap SA yaitu simulasi akreditasi. Tahap ini merupakan kegiatan terakhir dari serangkaian pendampingan, yaitu dengan melakukan simulasi akreditasi. Beberapa kegiatan yang dilakukan adalahmenyiapkan isian instrumen akreditasi, penataan tempat akreditasi, penataan dokumen data pendukung akreditasi, alur pelayanan dokumen akreditasi dan kegiatan lain yang terkait dengan visitasi akreditasi.

Selanjutnya untuk pelaksanaan dalam penelitian ini tahap 1 (BERKAT) dan 2 (EVADIR) dilaksanakan pada pra tindakan, sedangkan tahap 3 (BI) dilaksanakan pada siklus I/II dan tahap 4 (SA) dilaksanakan pada siklus II.

Melalui penerapan strategi ini diharapkan mampu membantu meningkatkan kompetensi manajerial kepala madrasah dalam mempersiapkan akreditasi.Strategi ini akan berhasil efektif jika pengawas sekolah melakukan pendampingan total dan sepenuh hati menjadi bagian tak terpisahkan dalam tim akreditasi di madrasah binaannya.

\section{B. Metode Penelitian}

Setting penelitian ini dilaksanakan di 3 Madrasah Aliyah (MA) binaan yaitu, MA Nahdatul Ulama Gondang, MA Nurul Huda Gondang dan MA Al Hikmah Tanon Kabupaten Sragen.Pemilihan tiga madrasah tersebut dengan alasan karena ketiga madrasah tersebut pada bulan Juni2017dijadwalkan reakreditasi oleh Badan Akreditasi Provinsi Sekolah/Madrasah (BAP S/M) Provinsi Jawa Tengah.Waktu penelitian ini dilakukan selama 4 bulan yaitu Februari sampai Mei 2017 pada semester genap Tahun Pelajaran 2016/2017 dilakukan dalam 2 siklus.Setiap siklus dilakukan 2 pertemuan dan 1 kali penilaian.

Subyek tindakan dalam penelitian ini adalah kepala madrasah yang melibatkan guru dan tenaga kependidikan.MA Nahdatul Ulama Gondang terdiri dari terdiri dari 1 orang kepala madrasah, 28 orang guru dan 3 orang tenaga kependidikan.MA Nurul Huda Gondang terdiri dari 1 orang kepala madrasah, 19 orang guru dan 4 orang tenaga kependidikan. Sedangkan MA Al Hikmah Tanon terdiri dari 1 orang kepala madrasah, 13orang guru dan 3 orang tenaga kependidikan.

Penelitian ini dalam pengumpulan data menggunakan metode observasi, wawancara, studi dokumen dan angket instrumen akreditasi. Sedangkan instrumen penelitian yang digunakan dalam penelitian ini adalah instrumen akreditasi Sekolah Menengah Atas/ MadrasahAliyah Tahun 2017 yang dituangkan dalamPeraturan Menteri Pendidikan dan Kebudayaan Nomor 004/H/AK/2017 tentang Kriteria dan Perangkat Akreditasi Sekolah Menengah Atas/Madrasah Aliyah (SMA/ MA).

Penelitian ini merupakan Penelitian Tindakan Sekolah (PTS) atauSchool Action Research (SAR) dengan menerapkan 
pendampingan model "BERKAT EVADIR BISA" yang merupakan akronim dari "bedah perangkat, evaluasi diri, bimbingan intensif dan simulasi akreditasi”. Keempat langkah ini dimplementasikan dalam serangkaian siklus kegiatan yang diawali dengan pra tindakan dan dilanjutkan dengan dua siklus kegiatan.Setiap siklus meliputi empat tahapan kegiatan, yaitu (1) perencanaan (planning); (2) pelaksanaan (acting); (3) pengamatan (observation); dan (4) refleksi (reflection).

\section{Hasil Penelitian dan Pembahasan}

\section{A. Deskripsi data Kondisi Awal}

Untuk memperoleh data awal penelitian sebagai acuan dalam melakukan tindakan selanjutnya, peneliti selaku pengawas sekolah melakukan kegiatan pra tindakan yaitu mengadakan sosialisasi perangkat akreditasi dengan bentuk kegiatan bedah perangkat akreditasi di masing-masing MA yang pesertanya adalah kepala madrasah sasaran dengan melibatkan guru dan tenaga kependidikan. Setelah kegiatan sosialisasi selesai, kegiatan dilanjutkan pengambilan data awal penelitian yaitu dengan melakukan penilaian atau evaluasi diri menggunakan instrumen akreditasi.

Dari hasil evaluasi diri di tiga MA binaan diperoleh data awal nilai persiapan akreditasi sebagai berikut: MA Nahdatul Ulama Gondang memperoleh nilai 75, MA Nurul Huda Gondang memperoleh nilai 77dan MA Al Hikmah Tanon memperoleh nilai 79.

\section{Siklus I}

Tindakan berupa bimbingan intensif oleh pengawas sekolah kepada kepala madrasah dalam mempersiapkan reakreditasi dilakukan dengan melibatkan seluruh guru dan tenaga kependidikan untuk menyiapkan data dan informasi pendukung akreditasi yang meliputi 8 komponen yaitu 1) standar isi; 2) standar proses; 3) standarkompetensi lulusan; 4) standar pendidik dan tenaga kependidikan; 5) standar sarana dan prasarana; 6) standar pengelolaan; 7) standar pembiayaan dan 8) standar penilaian. Dari hasil bimbingan intensif selama dua kali pertemuan, kemudian dilakukan penilaian I persiapan akreditasi di masing-masing MA,hasilnya adalah MA NU Gondang memperoleh nilai 86, MA Nurul Huda Gondang memperoleh nilai 88 dan MA Al Hikmah Tanon memperoleh nilai 84.

\section{SiklusII}

Tindakan berupa bimbingan intensif lanjutan oleh pengawas madrasah kepada kepala madrasah dalam mempersiapkan reakreditasi dilakukan dengan tetap melibatkan seluruh guru dan tenaga kependidikan untuk menyiapkan data dan informasi pendukung akreditasi yang meliputi 8 komponen yaitu 1) standar isi; 2) standar proses; 3) standarkompetensi lulusan; 4) standar pendidik dan tenaga kependidikan; 5) standar sarana dan prasarana; 6) standar pengelolaan; 7) standar pembiayaan dan 8) standar penilaian. Setelah bimbingan intensif lanjutan dilakukan selama dua kali pertemuan, kegiatan bimbingan diakhiri dengan simulasi akreditasi sekaligus dilakukan penilaian II persiapan akreditasi di masing-masing MA. Hasil penilaian simulasi akreditasi adalah MA NU Gondang memperoleh nilai 94, MA Nurul Huda Gondang memperoleh nilai 95 dan MA Al Hikmah Tanon memperoleh nilai 95.

\section{B. Hasil Tindakan}

Setelah dilakukan tindakan pada siklus I dan siklus II, nilai persiapan akreditasi yang mencakup 8 komponen yaitu 1) standar isi; 2) standar proses; 3) standar kompetensi lulusan; 4) standar pendidik dan tenaga kependidikan; 5) standar sarana dan prasarana; 6) standar pengelolaan; 7) standar pembiayaan dan 8) standar penilaian dari masing-masing MA mengalami peningkatan. Pada kondisi awal MA Nahdatul Ulama Gondang memperoleh nilai 75, MA Nurul Huda Gondang memperoleh nilai 77 dan MA Al Hikmah Tanon memperoleh nilai 79, pada siklus I nilai persiapan akreditasi meningkat, MA NU Gondang memperoleh nilai 86, MA Nurul Huda Gondang memperoleh nilai 
88 dan MA Al Hikmah Tanon memperoleh nilai 84 , dan pada siklus II juga mengalami peningkatan lagi, MA NU Gondang memperoleh nilai 94, MA Nurul Huda Gondang memperoleh nilai 95 dan MA Al
Hikmah Tanon memperoleh nilai 95. Adapun data nilai persiapan akreditasi ketiga MA mulai dari data awal, siklus I dan siklus II selengkapnya ada di tabel 1 .

Tabel 1. Data nilai persiapan akreditasi ketiga MA HASIL NILAI AWAL, SIKLUS I, SIKLUS II PERSIAPAN AKREDITASI MADRASAH ALIYAH

\begin{tabular}{|c|l|c|c|c|c|c|c|c|c|c|}
\hline \multirow{2}{*}{ No } & \multirow{2}{*}{ Komponen Akreditasi } & \multicolumn{3}{|c|}{ MA NU Gondang } & \multicolumn{3}{c|}{ MA Nurul Huda Gondang } & \multicolumn{3}{c|}{ MA AlHikmah Tanon } \\
\cline { 2 - 12 } & Awal & Siklus I & Siklus II & Awal & Siklus I & Siklus II & Awal & Siklus I & Siklus II \\
\hline 1 & Standar Isi & 80 & 98 & 100 & 75 & 98 & 100 & 81 & 95 & 100 \\
\hline 2 & Standar Proses & 77 & 96 & 98 & 75 & 92 & 98 & 81 & 93 & 99 \\
\hline 3 & Standar Kompetensi Lulusan & 75 & 89 & 97 & 75 & 90 & 100 & 89 & 92 & 96 \\
\hline 4 & $\begin{array}{l}\text { Standar Pendidik dan Tenaga } \\
\text { Kependidikan }\end{array}$ & 68 & 74 & 89 & 79 & 83 & 87 & 77 & 76 & 81 \\
\hline 5 & Standar Sarana dan Prasarana & 70 & 75 & 87 & 80 & 80 & 86 & 73 & 79 & 91 \\
\hline 6 & Standar Pengelolaan & 76 & 86 & 87 & 76 & 86 & 98 & 76 & 76 & 100 \\
\hline 7 & Standar Pembiayaan & 81 & 90 & 100 & 81 & 88 & 98 & 78 & 82 & 98 \\
\hline 8 & Standar Penilaian & 79 & 85 & 98 & 77 & 91 & 100 & 75 & 77 & 100 \\
\hline & Nilai Akreditasi & 75 & 86 & 94 & 77 & 88 & 95 & 79 & 84 & 95 \\
\hline
\end{tabular}

\section{Pembahasan}

Pada kondisi awal, ketiga MA yaitu MA Nahdatul Ulama Gondang, MA Nurul Huda Gondang dan MA Al Hikmah Tanon dalam mempersiapkan akreditasi menunjukkan tingkat kesiapan yang rendah atau kurang karena nilainya masing-masing baru mencapai predikat C (cukup). Setelah pengawas sekolah melakukan tindakan berupa bimbingan intensif pada siklus I dengan melibatkan kepala madrasah beserta seluruh guru dan tenaga kependidikan selama dua kali pertemuan di masing-masing MA maka hasil refleksinya menunjukkan ada peningkatan namun belum signifikan sehingga masih merekomendasikan agar kekurangan data dan informasi pendukung akreditasi yang masih belum ada dipenuhi secara maksimal. Pada siklus II pengawas sekolah melakukan tindakan berupa bimbingan intensif lanjutan kepada tim akreditasi yaitu kepala madrasah beserta seluruh guru dan tenaga kependidikan. Dengan motivasi pengawas selaku peneliti, tim akreditasi menunjukkan semangat kerja yang sangat tinggi untuk berusaha semaksimal mungkin memenuhi kekurangan data dan informasi yang belum ada dan menyempurnakan yang sudah ada agar bisa meraih predikat A. Kegiatan bimbingan intensif pengawas ini diakhiri dengan mengadakan simulasi akreditasi yang hasil refleksinya merekomendasikan hasil penilaian persiapan akreditasi telah mengalami peningkatan dan meraih predikat A, sehingga pemberian tindakan diakhiri sampai di sini atau tidak dilanjutkan lagi. Peningkatan nilai persiapan akreditasi dari pra tindakan, siklus I dan siklus II tersebut tergambar lebih jelas seperti sajian grafik berikut: 


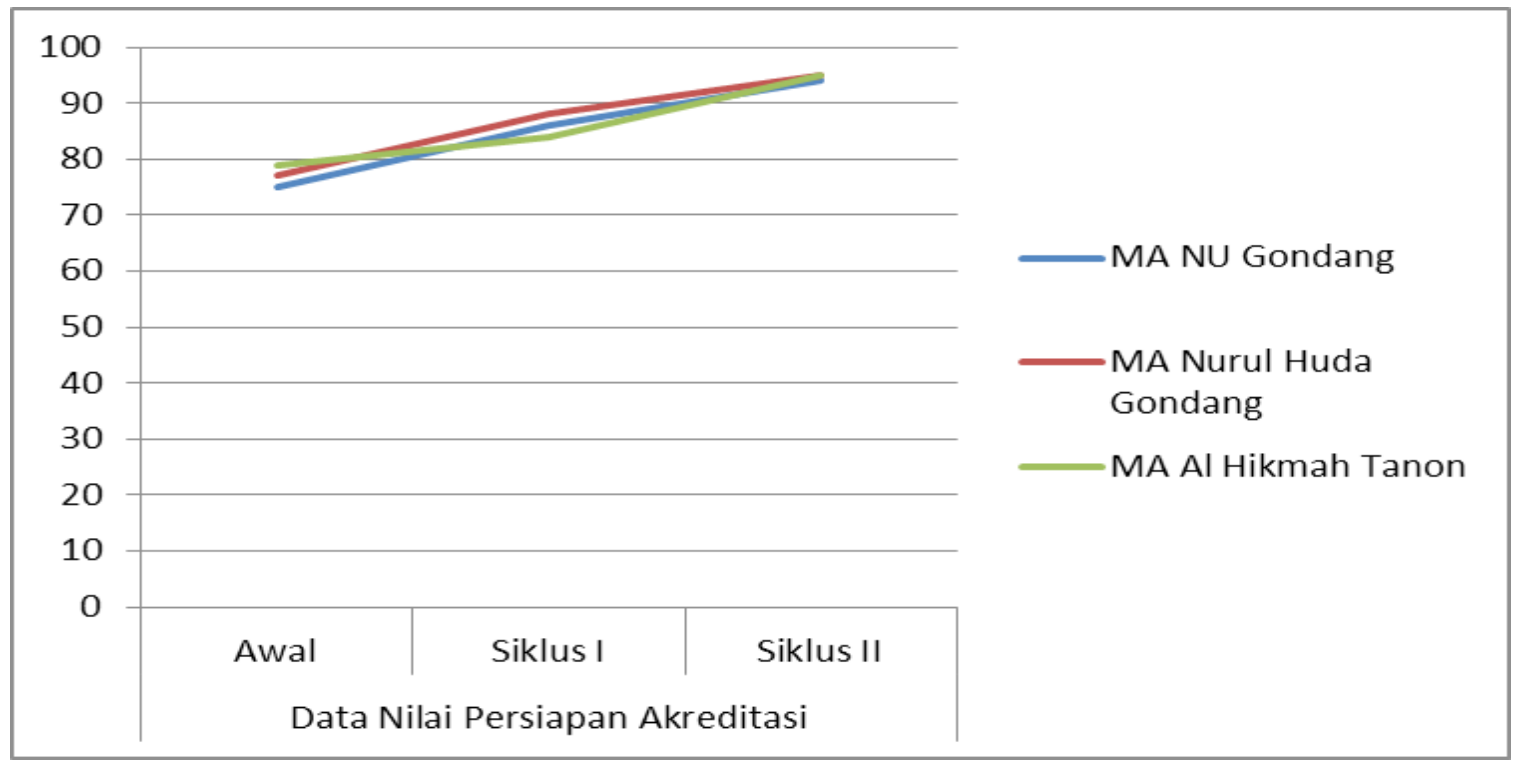

Grafik 1. Peningkatan nilai persiapan akreditasi dari pra tindakan, siklus I dan siklus II

Berangkat dari kondisi awal, kemudian didukung dengan data hasil tindakan pada siklus I dan siklus II yang didukung dengan tabel dan grafik menunjukkan bahwa telah terjadi peningkatan nilai persiapan akreditasi di MA Nahdatul Ulama Gondang, MA Nurul Huda Gondang dan MA Al Hikmah Tanon dengan menerapkan pendampingan model "BERKAT EVADIR BISA". Dengan demikian dapat dikatakan bahwa pendampingan model "BERKAT EVADIR BISA" mampu meningkatkan kompetensi kepala madrasah dalam mempersiapkan akreditasi.

\section{Simpulan}

Berdasarkan kajian teori dan hasil penelitian dapat diambil kesimpulan bahwa peningkatan kompetensi manajerial kepala madrasah dalam mempersiapkan akreditasi dapat dilakukan dengan menerapkan pendampingan model "BERKAT EVADIR
BISA" yang merupakan akronim dari bedah perangkat akreditasi, evaluasi diri, bimbingan intensif, dan simulasi akreditasi.

\section{Saran}

Berdasarkan kesimpulan penelitian ini, peneliti menyampaikan saran sebagai berikut: (1) Pengawas sekolah yang madrasah binaannya akan melaksanakan akreditasi dalam melakukan pendampingan kepada kepala madrasah dapat menerapkan model "BERKAT EVADIR BISA" yang merupakan akronim dari bedah perangkat, evaluasi diri, bimbingan intensif, dan simulasi; (2) Kepala madrasah beserta guru dan tenaga kependidikan agar selalu membiasakan budaya tertib administrasi sehingga sewaktu ada jadwal akreditasi seluruh dokumen data dan informasi pendukung akreditasi yang diperlukan sudah tersedia secara memadai tanpa harus kerja lembur.

\section{Daftar Pustaka}

Direktorat Jenderal Peningkatan Mutu Pendidik dan Tenaga Kependidikan.Departemen Pendidikan Nasional. 2009. Dimensi Kompetensi Supervisi Manajerial.Bahan Belajar Mandiri KKPS.

Direktorat Jenderal Peningkatan Mutu Pendidik dan Tenaga Kependidikan.Departemen Pendidikan Nasional. 2009. Penelitian Tindakan Sekolah.Bahan Belajar Mandiri KKPS. Direktorat Tenaga Kependidikan. Direktorat Jenderal Peningkatan Mutu Pendidik dan Tenaga 
Kependidikan.Departemen Pendidikan Nasional. 2008. Monitoring Pelaksanaan Standar Nasional Pendidikan dan Akreditasi Sekolah.

Edy Pudiyanto.2015. Supervisi Manajerial. Materi Penguatan Pengawas Sekolah Kabupaten Sragen.

Kementerian Pendidikan dan Kebudayaan, Direktorat Jenderal Guru dan Tenaga Kependidikan,

Direktorat Pembinaan Tenaga Kependidikan Pendidikan Dasar dan Menengah.2017. Panduan Kerja Pengawas Sekolah Pendidikan Dasar dan Menengah.

Madyo Ekosusilo. 2012. Karya Tulis Ilmiah (KTI) Bidang Kepengawasan.Materi Bimbingan

Teknis Calon Penilai Angka Kredit Tingkat Kabupaten/Kota/Propinsi.Direktorat Pembinaan PTK Dirjen Pendidikan Menengah Kementerian Pendidikan dan Kebudayaan.

Peraturan Menteri Pendayagunaan Aparatur Negara dan Reformasi Birokrasi Nomor 14 Tahun 2016 tentang Perubahan atas Peraturan Menteri Pendayagunaan Aparatur Negara dan Reformasi Birokrasi Nomor 21 Tahun 2010 tentang Jabatan Fungsional Pengawas Sekolah dan Angka Kreditnya.

Peraturan Menteri Pendidikan dan Kebudayaan Nomor 004/H/AK/2017 tentang Kriteria dan Perangkat Akreditasi Sekolah Menengah Atas/Madrasah Aliyah (SMA/MA)

Peraturan Menteri Pendidikan Nasional Nomor 12 Tahun 2007 tentang Standar Pengawas Sekolah/Madrasah.

Peraturan Menteri Pendidikan Nasional Nomor 13 Tahun 2007 tentang Kepala Sekolah Sekolah/Madrasah.Departemen Pendidikan Nasional. Jakarta.

Peraturan Pemerintah Repulik Indonesia Nomor 74 Tahun 2008 tentang Guru.

Peraturan Pemerintah Republik Indonesia Nomor 17 Tahun 2010 tentang Pengelolaan dan Penyelenggaraan Pendidikan.

Peraturan Pemerintah Republik Indonesia nomor 13 Tahun 2015 tentang Perubahan Kedua atas Peraturan Pemerintah Nomor 19 Tahun 2005 tentang Standar Nasional Pendidikan.

Peraturan Pemerintah Republik Indonesia Nomor 19 Tahun 2005 tentang Standar Nasional Pendidikan.

Suharsimi Arikunto, Suhardjono, Supardi. 2006. Penelitian Tindakan Kelas. Jakarta. PT Bumi Aksara.

Supardi, Suhardjono. 2013. Strategi Menyusun Penelitian Tindakan Kelas. Berdasarkan Permenpan dan Reformasi Birokrasi No. 16 Tahun 2009.Yogyakarta.Penerbit Andi Offset.

Undang-Undang Republik Indonesia Nomor 20 Tahun 2003 tentang Sistem Pendidikan Nasional. 